\title{
Liposomal encapsulation enhances and prolongs the anti-inflammatory effects of water-soluble dexamethasone phosphate in experimental adjuvant arthritis
}

Rebecca Anderson ${ }^{1,2}$, Angels Franch², Margarida Castell ${ }^{2}$, Francisco J Perez-Cano ${ }^{2}$, Rolf Bräuer ${ }^{3}$, Dirk Pohlers ${ }^{1}$, Mieczyslaw Gajda ${ }^{3}$, Alexandros P Siskos ${ }^{4}$, Theodora Katsila ${ }^{4}$, Constantin Tamvakopoulos ${ }^{4}$, Una Rauchhaus ${ }^{5}$, Steffen Panzner ${ }^{5}$, Raimund W Kinne ${ }^{1 *}$

\begin{abstract}
Introduction: The objective of this study was to evaluate the efficacy of intravenous (i.v.) injection of liposomally encapsulated dexamethasone phosphate (DxM-P) in comparison to free DxM-P in rats with established adjuvant arthritis (AA). This study focused on polyethylene glycol (PEG)-free liposomes, to minimize known allergic reactions caused by neutral PEG-modified (PEG-ylated) liposomes.

Methods: Efficacy was assessed clinically and histologically using standard scores. Non-specific and specific immune parameters were monitored. Activation of peritoneal macrophages was analyzed via cytokine profiling. Pharmacokinetics/biodistribution of DxM in plasma, synovial membrane, spleen and liver were assessed via mass spectrometry.

Results: Liposomal DxM-P $(3 \times 1$ mg/kg body weight; administered intravenously (i.v.) on Days 14, 15 and 16 of AA) suppressed established AA, including histological signs, erythrocyte sedimentation rate, white blood cell count, circulating anti-mycobacterial IgG, and production of interleukin-1 beta $(\mathrm{IL}-1 \beta)$ and IL-6 by peritoneal macrophages. The suppression was strong and long-lasting. The clinical effects of liposomal DxM-P were dose-dependent for dosages between 0.01 and $1.0 \mathrm{mg} / \mathrm{kg}$. Single administration of $1 \mathrm{mg} / \mathrm{kg}$ liposomal DxM-P and $3 \times 1 \mathrm{mg} / \mathrm{kg}$ of free DxM-P showed comparable effects consisting of a partial and transient suppression. Moreover, the effects of medium-dose liposomal DxM-P $(3 \times 0.1 \mathrm{mg} / \mathrm{kg})$ were equal (in the short term) or superior (in the long term) to those of high-dose free DxM-P $(3 \times 1 \mathrm{mg} / \mathrm{kg})$, suggesting a potential dose reduction by a factor between 3 and 10 by liposomal encapsulation. For at least 48 hours after the last injection, the liposomal drug achieved significantly higher levels in plasma, synovial membrane, spleen and liver than the free drug.

Conclusions: This new PEG-free formulation of macrophage-targeting liposomal DxM-P considerably reduces the dose and/or frequency required to treat AA, with a potential to enhance or prolong therapeutic efficacy and limit side-effects also in the therapy of rheumatoid arthritis. Depot and/or recirculation effects in plasma, inflamed joint, liver, and spleen may contribute to this superiority of liposomally encapsulated DxM-P.
\end{abstract}

\footnotetext{
* Correspondence: Raimund.W.Kinne@med.uni-jena.de

${ }^{1}$ Experimental Rheumatology Unit, Department of Orthopedics, University Hospital Jena, Klosterlausnitzer Str. 81, 07607 Eisenberg, Germany
} 


\section{Introduction}

Rheumatoid arthritis (RA) is a systemic disorder of unknown etiology characterized by chronic inflammation and symmetric, progressive destruction of arthritic joints. The abundance and activation of macrophages $(M \varphi)$ in the inflamed synovial membrane significantly correlates with the severity of RA [1,2]. In addition, activation of the monocytic lineage extends to systemic parts of the mononuclear phagocyte system [3-7]. Thus, selective counteraction of $M \varphi$ activation is a promising approach to diminish local and systemic inflammation or to prevent irreversible joint damage.

In addition to disease-modifying anti-rheumatic drugs (DMARDs) and to recently introduced biologicals (for example, antibodies against tumor necrosis factor(TNF)- $\alpha$ or soluble TNF- $\alpha$-receptors, [8-14]), antiinflammatory glucocorticoids are still frequently employed to bridge the gap before the onset of action of DMARDs [15-17] and to improve the therapeutic control of RA. Due to their unequalled efficacy, bridging application and wide indication range (for example, renal failure, pregnancy), glucocorticoids remain valuable therapeutic tools. However, concerns about longterm side effects, such as Cushing syndrome or bone demineralization, strongly emphasize the need for safer treatment modalities. Specific targeting of glucocorticoids to phagocytic cells by liposomal encapsulation potentially increases drug efficacy and longevity while minimizing side-effects $[18,19]$.

Previous studies have demonstrated good therapeutic efficacy of water-soluble prednisolone in neutral polyethylene glycol-modified (PEGylated) liposomes in animal models of arthritis and multiple sclerosis [20-23]. However, evidence has emerged that repeated injections can result in the generation of anti-PEG antibodies, emphasizing the need for a PEG-free liposomal formulation [24-27].

In this study, water-soluble dexamethasone phosphate (DxM-P) was encapsulated in a novel, non-PEGylated liposome formulation (Micromethason). All lipids in this formulation have market approval, thereby minimizing the risk of lipid-associated toxicity. The efficacy of liposomal DxM-P was evaluated in rat adjuvant arthritis (AA), a severe animal model characterized by histopathological similarities to RA, including both systemic and local features of inflammation [28]. The effects of treatment with free DxM-P or different doses of liposomally-encapsulated DxM-P were also evaluated, in order to assess the increase of therapeutic potency by encapsulation. In addition, a pharmacokinetics and biodistribution study of DxM was carried out following administration of liposomal DxM-P or free DxM-P.

\section{Materials and methods}

\section{Micromethason preparation}

Micromethason liposomes were prepared by Novosom AG (Halle, Germany) from 1,2-dipalmitoyl-sn-glycero-3phosphocholine (DPPC), 1,2-dipalmitoyl-sn-glycero-3(phosphor-rac-(1-glycerol))(sodium salt) (DPPG) and cholesterol (50:10:40 mol \%; all lipids with market approval) using the lipid film extrusion method [29]. The lipid film was hydrated with DxM-P $(25 \mathrm{mg} / \mathrm{ml}$ in phosphate-buffered saline (PBS), $\mathrm{pH} 7.5$ ) and the resulting vesicles were extruded through $400 \mathrm{~nm}$ membranes. Non-encapsulated DxM-P was removed by gel filtration. Particle size $(283$ to $310 \mathrm{~nm})$ and polydispersity $(\leq 0.3)$ were determined by dynamic light scattering. The drug/ lipid ratio was $40 \mu \mathrm{g} / \mu \mathrm{mol}$ (determined as in [30]) and the concentration was adjusted to $500 \mu \mathrm{g}$ DxM-P/ml.

The liposomes were selected for tolerability in vivo and their ability to target cells of the macrophage-phagocyte system while avoiding unwanted sites such as the liver parenchyme. The latter was achieved by using rather large particles, which cannot penetrate across the $150 \mathrm{~nm}$ fenestrations of liver endothelium [31]. The cellular targeting to cells of the macrophage-phagocyte system relates to the negative surface charge of the liposomes [32].

\section{Adjuvant arthritis Animals}

Female Lewis rats (seven to eight weeks of age) were obtained from Harlan (Barcelona, Spain) and housed three to four per cage under standard conditions, with food and water ad libitum and a 12-hour-light/12-hourdark cycle. The animals were allowed two weeks to adjust to the housing conditions prior to the initiation of studies. The experiments were performed in accordance with the Institutional Guidelines for the Care and Use of Laboratory Animals (Ethics Committee for Animal Experimentation, Universities of Barcelona and Jena).

\section{Experimental design}

On Day 0, rats were injected intradermally (i.d.) into the tail base with $0.5 \mathrm{mg}$ of heat-killed Mycobacterium butyricum (Mb) (Difco, Detroit, MI, USA) in $0.1 \mathrm{ml}$ of liquid vaseline as previously published [33]. Only animals developing clear signs of arthritis on Day 14 (arthritis score $\geq 2$ ) were used for further studies $(n=6$ for all groups). On Days 14, 15 and 16 of AA, anesthetized rats were treated intravenously (i.v.; tail vein) with $1 \mathrm{mg} / \mathrm{kg}$ body weight liposomal DxM-P (AA/DxM-Pliposomes; usually $250 \mu \mathrm{g} / 250 \mathrm{~g}$ body weight). Arthritic controls were injected with either $3 \times 1 \mathrm{mg} / \mathrm{kg}$ body weight of free DxM-P (AA/DxM-P), an equal volume of PBS (AA/PBS), or PBS-containing liposomes (AA/PBSliposomes). The healthy controls were not immunized 
and did not receive any treatment. For dose-response studies, animals were treated with $3 \times 0.01 \mathrm{mg} / \mathrm{kg}, 3 \times$ $0.1 \mathrm{mg} / \mathrm{kg}$, or $3 \times 1 \mathrm{mg} / \mathrm{kg}$ of liposomal or free DxM-P. In addition, one group of rats received a single dose of $1 \mathrm{mg} / \mathrm{kg}$ of liposomal DxM-P on Day 14 of AA. In total, three different arthritis studies were performed, that is, Experiment 1 (treatment study; see Table 1 and Figure 1), Experiment $2 / 3$ (two different animal subgroups of the same treatment study containing both groups with triple and single treatment with liposomal DxM; Table 1), and Experiment 4 (dose response; see Table 2 and Figure 2).

\section{Clinical parameters}

Clinical signs of AA were assessed by measuring body weight (precision scale), arthritis score (blinded grading of each paw from 0 to 4 according to the extent of edema and erythema of the periarticular tissue, as well as the deformation of the joint; maximal score per animal: 16), and hind paw volume (water plethysmometer; LI 7500 Letica, Spain). Except for the healthy controls, all groups were normalized to the same mean value for each parameter on Day 14; the volume of both hind paws was averaged.

\section{Histology}

Animals were sacrificed on Day 21 of AA (that is, shortly after the maximal efficacy of therapy) and the hind paws were removed, skinned, fixed in $3 \%$ paraformaldehyde, decalcified, and embedded in paraffin. Microtome sections ( 3 to $5 \mu \mathrm{m}$ ) of decalcified joints were deparaffinized and stained with hematoxylin and eosin (HE). Severity of arthritis was examined by blinded grading of acute inflammation (graded from 0 (absent) to 9 (very severe) according to the magnitude of granulocyte infiltration and exudates) and chronic inflammation (graded from 0 to 9 according to the magnitude of synovial hyperplasia, mononuclear infiltration, and affection of periarticular structures), as well as joint and bone destruction (each graded from 0 to 3). Parameters were semi-quantitatively judged by an experienced pathologist (MG).

Erythrocyte sedimentation rate (ESR), white blood cell count (WBC), and differential leukocyte count

Blood samples were obtained by cardiac puncture of anesthetized rats on Day 21 of AA. To determine the ESR, $1 \mathrm{ml}$ of tri-sodium citrate-treated blood was left to sediment for one hour in capillaries (Tapval ${ }^{\mathrm{TM}}$ tubes, Aquisel, Barcelona, Spain). The WBC was determined automatically using a Coulter Counter JT hemocytometer (Hialeah, FL, USA) calibrated for rat blood, and the differential white blood count was obtained by manual enumeration of May-Grünwald-Giemsa-stained blood cell smears.

\section{Determination of serum anti-Mb antibodies}

Anti-Mb immunoglobulin G (IgG) in rat sera (diluted $1: 1.000$ and $1: 10.000$ in BSA/PBS/0.05\% Tween) was measured by ELISA using Mb-coated microplates $(3 \mu \mathrm{g} /$ $\mathrm{ml}$ of mycobacterial protein) as previously published $[33,34]$.

\section{Delayed-type hypersensitivity}

To assess the delayed-type hypersensitivity (DTH), $50 \mu \mathrm{l}$ $\mathrm{Mb}(1.5 \mathrm{mg} / \mathrm{ml}$ of PBS $)$ and $50 \mu \mathrm{l}$ PBS, respectively, were injected intradermally into the left and right ear on

Table 1 Reduction of clinical parameters by liposomal dexamethasone phosphate on Days 19 and 28 of adjuvant arthritis

\begin{tabular}{|c|c|c|c|c|}
\hline \multirow{2}{*}{$\begin{array}{l}\text { Experiment } 1 \\
\text { Treatment }\end{array}$} & \multicolumn{2}{|c|}{ Arthritis score } & \multicolumn{2}{|c|}{ Paw volume } \\
\hline & Day 19 & Day 28 & Day 19 & Day 28 \\
\hline$A A / P B S$ & - & - & - & - \\
\hline AA/PBS-liposomes & $+23 \% \pm 29.4 \%$ & $+36 \% \pm 56.5 \%$ & $+2 \% \pm 38.8 \%$ & $+47 \% \pm 62.3 \%$ \\
\hline$A A D \times M-P$ & $-51 \% \pm 17.8 \%$ & $+4 \% \pm 41.7 \%$ & $-65 \% \pm 14.0 \%$ & $-13 \% \pm 26.4 \%$ \\
\hline AAliposomal DXM-P & $-95 \% \pm 3.2 \%^{++\# \#}$ & $-54 \% \pm 28.7 \%$ & $-92 \% \pm 7.4 \%{ }^{++\#}$ & $-73 \% \pm 17.3 \%^{+}$ \\
\hline Experiment $2 / 3$ & \multicolumn{2}{|c|}{ Arthritis score } & \multicolumn{2}{|c|}{ Paw volume } \\
\hline Treatment & Day 19 & Day 29* & Day 19 & Day 29* \\
\hline AAVPBS & - & - & - & - \\
\hline AAVPBS-liposomes & $+15 \% \pm 19.8 \%$ & & $+23 \% \pm 20.3 \%$ & \\
\hline$A A N D \times M-P$ & $-67 \% \pm 16.4 \%+\#$ & & $-52 \% \pm 21.8 \%+\#$ & \\
\hline AAlliposomal DXM-P & $-90 \% \pm 5.0 \%{ }^{++\# \#}$ & & $-87 \% \pm 6.6 . \%^{++\# \#}$ & \\
\hline AAliposomal DXM-P $1 x^{*}$ & $-48 \% \pm 23.9 \%$ & $-15 \% \pm 29.6 \%$ & $-63 \% \pm 24.6 \%$ & $-35 \% \pm 22.6 \%$ \\
\hline
\end{tabular}

Reduction of arthritis score and paw volume on Day 19 (maximal efficacy of therapy) and Day 28 of AA after treatment with PBS-liposomes, free DxM-P (3 $\times 1$ $\mathrm{mg} / \mathrm{kg}$; Days 14, 15 and 16), or liposomal DxM-P $(3 \times 1 \mathrm{mg} / \mathrm{kg}$; Days 14, 15 and 16) compared to AA/PBS (Experiment 1 corresponds to the data in Figure 1). For comparison, the effects of treatment with single-dose liposomal DxM-P $(1 \times 1 \mathrm{mg} / \mathrm{kg}$; Day 14; Experiment 3$)$ are shown. * results from a separate subgroup of animals (named Experiment 3 for clarity) from the same arthritis study with similar disease severity on Days 19 and 20 as the other subgroup of animals (named Experiment 2).

Data are expressed as means \pm standard error of the mean.

$+P \leq 0.05,++P \leq 0.01$ vs. AA/PBS; \# $P \leq 0.05$, \#\# $P \leq 0.01$ vs. PBS-liposomes. 

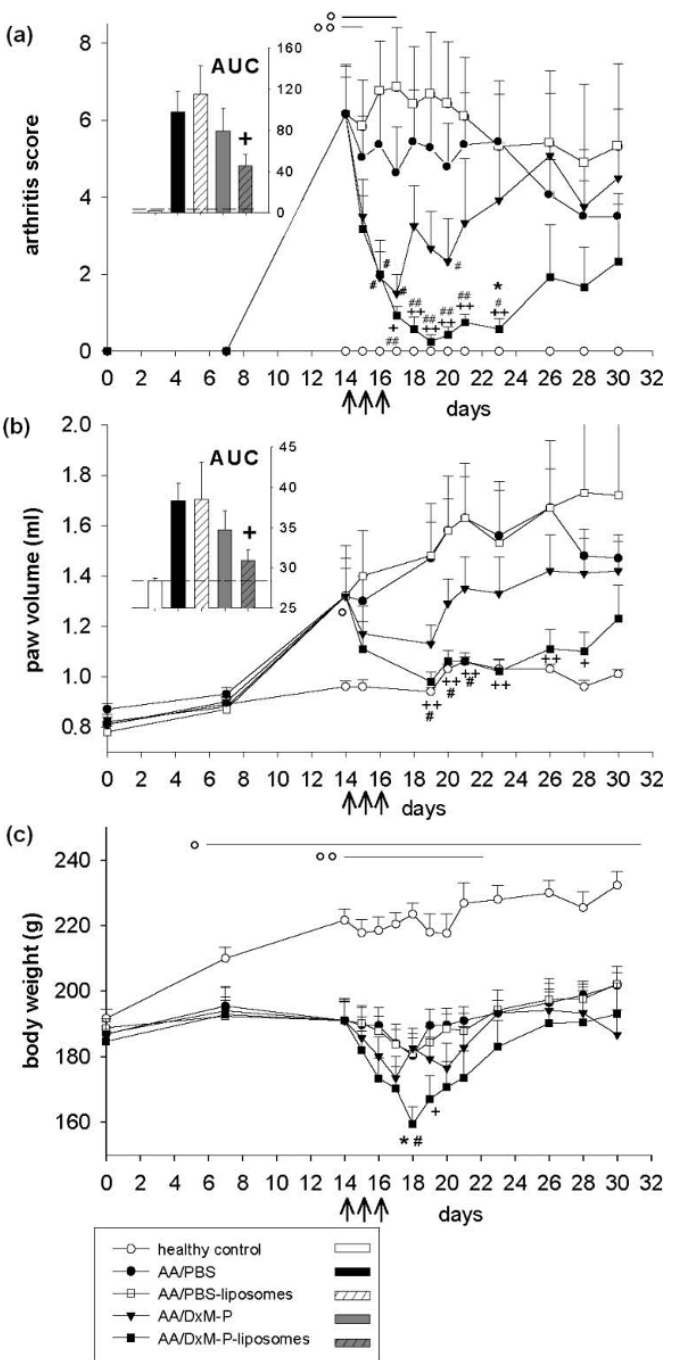

Figure 1 Clinical effects of free or liposomal DxM-P in adjuvant arthritis (Experiment 1). Effect of treatment with PBS-liposomes, free DxM-P $(3 \times 1 \mathrm{mg} / \mathrm{kg}$; Days 14, 15 and 16), or liposomal DxM-P $(3 \times 1 \mathrm{mg} / \mathrm{kg}$; Days 14, 15 and 16) on arthritis score (a), paw volume (b), and body weight (c); all arthritic groups were normalized to the same mean value for each parameter on Day 14 ( $n=6$ each). The inserts show the area under the curve (AUC) from Day 0 to Day 30 for the arthritis score (a) and the paw volume (b); dashed line: healthy control levels. For all treatment groups: $+P \leq$ $0.05,++P \leq 0.01$ vs. AA/PBS; \# $P \leq 0.05$, \#\# $P \leq 0.01$ vs. AA/PBSliposomes; ${ }^{*} P \leq 0.05$ vs. AA/DxM-P; For AA/liposomal DxM-P: O $P \leq$ 0.05 , oo $P \leq 0.01$ vs. healthy controls; all Mann Whitney U-test; $\uparrow$ I. v. administration of PBS, PBS-liposomes, free DxM-P, or liposomal DxMP.

Day 19 (that is, 48 hours prior to sacrifice). The ears of anesthetized rats were cut, weighed, and the DTH was expressed as the $\mathrm{x}$-fold enlargement in comparison to the contra-lateral control ear.

\section{Isolation of spleen and lymph node lymphocytes}

Spleen and popliteal lymph nodes (the latter as draining node of the arthritic hind paw; pop LN) were obtained on Day 21. Spleen cell suspensions were prepared by passing the samples through stainless steel sieves and eliminating the erythrocytes by hypotonic lysis (consecutive resuspension in $1 \mathrm{ml}$ sterile $\mathrm{PBS}, 8 \mathrm{ml} \mathrm{H} \mathrm{H}_{2} \mathrm{O}$, and 1 $\mathrm{ml} 10 \times \mathrm{PBS}$ ). Pop LN were passed through stainless steel sieves and sterile gauze to eliminate connective tissue. After centrifugation (10 minutes; $600 \times g)$, cell suspensions were resuspended in RPMI 1640 plus $10 \%$ FBS, and the lymphocytes counted using Fast $\operatorname{Read}^{\odot}$ chamber slides under fluorescence light after vital staining with acridine orange and ethidium bromide.

\section{Isolation and stimulation of peritoneal $M \varphi$ (PM)}

$P M$ were harvested on Day 21 by peritoneal lavage with $40 \mathrm{ml}$ ice-cold PBS, centrifuged, washed, and resuspended in RPMI 1640 containing 10\% FCS and 5\% gentamycine. Adherent $\mathrm{M} \varphi\left(1 \times 10^{6}\right.$ cells per well of 12 well plates after adherence for two hours at $37^{\circ} \mathrm{C}$ ) were stimulated for 24 hours with LPS $(1 \mu \mathrm{g} / \mathrm{ml}$; E coli; Serotype 0111:B4; Sigma-Aldrich, Munich, Germany). Cytokines were analyzed in cell-free supernatants by ELISA using rat TNF- $\alpha$ and rat IL-6 (BD Biosciences Pharmingen, San Diego, CA, USA) or rat IL- $1 \beta$ kits (R\&D Systems, Minneapolis, MN, USA).

\section{Pharmacokinetics/biodistribution}

The analysis of DxM concentrations in different body compartments was performed as previously published with slight modifications $[35,36]$.

\section{Materials}

HPLC-grade acetonitrile $(\mathrm{AcCN})$ was purchased from Fisher Scientific (Loughborough, UK). HPLC-grade ammonium acetate $\left(\mathrm{NH}_{4} \mathrm{Ac}\right)$ and $\mathrm{HPLC}$-grade formic acid (FA) were purchased from Sigma-Aldrich (Athens, Greece). Purified water was produced using a Barnstead NANOpure Diamond water system from Barnstead International (Dubuque, IA, USA). DxM and prednisolone were purchased from Riedel-de Haen (ChemiLab, Athens, Greece).

\section{Preparation of standards and calibration curve for method validation}

Prednisolone was used as an internal standard (IS) for the quantitative analysis of DxM. Stock solutions of both DxM (5 to $10,000 \mathrm{ng} / \mathrm{ml})$ and prednisolone $(1 \mu \mathrm{g} / \mathrm{ml})$ were prepared in methanol. Calibration curves (2 to $4,000 \mathrm{ng} /$ $\mathrm{ml}$; limit of quantification $2 \mathrm{ng} / \mathrm{ml}$ ) and quality control samples $(800 \mathrm{ng} / \mathrm{ml})$ in plasma were prepared daily by adding $20 \mu \mathrm{l}$ of DxM and $20 \mu \mathrm{l}$ of IS solutions into $50 \mu \mathrm{l}$ of plasma. For tissue analysis, calibration curves were constructed daily in a similar manner by adding standards of DxM and IS into $100 \mu \mathrm{l}$ of tissue homogenate (liver, spleen or synovial membranes) at concentrations of 2.5 to 2,000 $\mathrm{ng} / \mathrm{g}$ (limit of quantification $2.5 \mathrm{ng} / \mathrm{g}$ ). Calibration curves were constructed using a linear fit $\left(1 / \mathrm{x}^{2}\right.$ weighing) in the concentration range of 2 to $4,000 \mathrm{ng} / \mathrm{ml}$ for plasma and 2.5 to $2,000 \mathrm{ng} / \mathrm{g}$ for the tissues. The accuracy in the 
Table 2 Dose-dependent reduction of clinical parameters by liposomal dexamethasone phosphate on Days 19 and 28 in adjuvant arthritis

\begin{tabular}{|c|c|c|c|c|c|}
\hline \multirow{2}{*}{$\begin{array}{l}\text { Experiment } 4 \\
\text { Treatment }\end{array}$} & & \multicolumn{2}{|c|}{ Arthritis score } & \multicolumn{2}{|c|}{ Paw volume } \\
\hline & & Day 19 & Day 28 & Day 19 & Day 28 \\
\hline AAVPBS & & - & - & - & - \\
\hline$A A D \times M-P$ & $0.01 \mathrm{mg} / \mathrm{kg}$ & $-10 \% \pm 9.3 \%$ & $+6 \% \pm 11.9 \%$ & $-18 \% \pm 12.9 \%$ & $-12 \% \pm 8.4 \%$ \\
\hline$A A D \times M-P$ & $0.1 \mathrm{mg} / \mathrm{kg}$ & $-25 \% \pm 6.9 \%$ & $-4 \% \pm 10.3 \%$ & $-34 \% \pm 10.1 \%$ & $+9 \% \pm 27.0 \%$ \\
\hline$A A N D \times M-P$ & $1.0 \mathrm{mg} / \mathrm{kg}$ & $-69 \% \pm 12.5 \%+$ & $-27 \% \pm 16.4 \%$ & $-71 \% \pm 10.4 \%+$ & $-23 \% \pm 16.0 \%$ \\
\hline AAliposomal DxM-P & $0.01 \mathrm{mg} / \mathrm{kg}$ & $-20 \% \pm 14.0 \%$ & $-13 \% \pm 18.5 \%$ & $-21 \% \pm 21.1 \%$ & $-5 \% \pm 26.7 \%$ \\
\hline AAliposomal DxM-P & $0.1 \mathrm{mg} / \mathrm{kg}$ & $-38 \% \pm 23.7 \%$ & $-28 \% \pm 16.9 \%$ & $-44 \% \pm 15.4 \%$ & $-36 \% \pm 12.2 \%$ \\
\hline AAliposomal DxM-P & $1.0 \mathrm{mg} / \mathrm{kg}$ & $-96 \% \pm 2.0 \%+\$ \$ \S *$ & $-59 \% \pm 20.0 \%$ & $-86 \% \pm 5.1 \%++\$ \$ \S \S$ & $-58 \% \pm 18.0 \%$ \\
\hline
\end{tabular}

Reduction of arthritis score and paw volume on Day 19 (maximal efficacy of therapy) and Day 28 of AA after treatment with free DxM-P ( $3 \times 1$ mg/kg, $3 \times 0.1$ $\mathrm{mg} / \mathrm{kg}$, or $3 \times 0.01 \mathrm{mg} / \mathrm{kg})$ or liposomal DxM-P $(3 \times 1 \mathrm{mg} / \mathrm{kg}, 3 \times 0.1 \mathrm{mg} / \mathrm{kg}$, or $3 \times 0.01 \mathrm{mg} / \mathrm{kg})$ compared to AA/PBS (Experiment 4 corresponds to the data in Figure 2).

Data are expressed as means \pm standard error of the mean

$+P \leq 0.05,++P \leq 0.01$ vs. AA/PBS; $\$ P \leq 0.01$ vs. AA/liposomal DxM-P $0.01 \mathrm{mg} / \mathrm{kg} ; \S P \leq 0.05, \S \S P \leq 0.01$ vs. AA/liposomal DxM-P $0.1 \mathrm{mg} / \mathrm{kg} ;{ }^{*} P \leq 0.05$ vs. AA/ DxM-P $1 \mathrm{mg} / \mathrm{kg}$.

concentration range was $\pm 20 \%$ (that is, target concentrations were within $20 \%$ of nominal values). The recovery of DxM was evaluated in rat plasma $(96 \%$ at a concentration of $200 \mathrm{ng} / \mathrm{ml})$ and in rat liver $(91 \%$ at a concentration of $1,000 \mathrm{ng} / \mathrm{g})$.

\section{Tissue/organ sampling}

Heparinized plasma samples were obtained by retroorbital puncture and subsequent centrifugation $30 \mathrm{~min}-$ utes, 2 hours, 8 hours, and 24 hours after the first administration of free or liposomal DxM-P $(1 \mathrm{mg} / \mathrm{kg}$ each; $1^{\text {st }}$ administration $=$ time point 0 for pharmacokinetic results; Day 14 of AA), as well as 72 hours, 96 hours, and 9 days after the first dose (these animals received a total of three drug administrations). Synovial membrane, spleen, and liver where also obtained 72 hours, 96 hours, and 9 days after the first injection (total of three doses); all samples were immediately shock frozen in liquid nitrogen.

\section{Sample preparation}

Plasma Prior to the extraction procedure, $20 \mu \mathrm{l}$ of the IS solution was added to $50 \mu \mathrm{l}$ of mouse plasma. Samples were prepared for LC/ESI-MS/MS analysis by protein precipitation by addition of $100 \mu \mathrm{l}$ acetonitrile:water (50:50), followed by stepwise addition of $(2 \times 150 \mu \mathrm{l})$ of ice-cold acetonitrile and brief vortexing and sonication. The samples were subsequently centrifuged $(12,000 \times g)$ for 15 minutes, and the supernatant was transferred into glass tubes and evaporated in a SpeedVac SPD1010 (Thermo Fisher Scientific Inc., Waltham, MA, USA) for 70 minutes at $50^{\circ} \mathrm{C}$. Until analyzed, samples were stored at $-20^{\circ} \mathrm{C}$. An aliquot of $200 \mu \mathrm{l}$ of mobile phase of the initial chromatographic conditions A/B 95/5 was added to each sample, vortexed, and transferred onto a 96-well plate for analysis by LC/ESI-MS/MS.

Tissues/organs Synovial membrane, spleen, or liver homogenates were prepared as follows: tissues were washed once with $5 \mathrm{ml}$ of water. Water was decanted after washing and $4 \mathrm{ml}$ of $0.1 \%$ formic acid in water per $\mathrm{g}$ of tissue were added to the respective tissues. The mixture was homogenized in an Ultra-Turrax T8 homogenizer (IKA ${ }^{\oplus}$-Werke, Germany) and subsequent analysis was carried out immediately after homogenization. Prior to the extraction of DxM from tissue homogenates, 20 $\mu \mathrm{l}$ of the IS solution was added to $100 \mu \mathrm{l}$ of tissue homogenate. Samples were prepared for LC/ESI-MS/MS analysis by protein precipitation via addition of $200 \mu \mathrm{l}$ acetonitrile:water (50:50), followed by stepwise addition of $(2 \times 300 \mu \mathrm{l})$ of ice-cold acetonitrile and brief vortexing/sonication. The samples were subsequently centrifuged for 15 minutes, and the supernatant was transferred into glass tubes and evaporated in a SpeedVac SPD1010 for 70 minutes at $50^{\circ} \mathrm{C}$. Samples were stored at $-20^{\circ} \mathrm{C}$. An aliquot of $100 \mu \mathrm{l}$ of mobile phase of the initial chromatographic conditions A/B 95/5 was added to each sample, vortexed, and transferred onto a 96-well plate for analysis by LC/ESI-MS/MS.

\section{LC-MS/MS analysis}

HPLC was performed with an Agilent 1100 Series system (Agilent Technologies, Waldbrown, Germany) equipped with a binary pump, autosampler, vacuum degasser, and temperature-controlled column compartment. The mobile phase consisted of solvents A: $10 \%$ acetonitrile, 90\% water, $2 \mathrm{mM}$ ammonium acetate, $0.1 \%$ formic acid and B: $90 \%$ acetonitrile, $10 \%$ water, $2 \mathrm{mM}$ ammonium acetate, $0.1 \%$ formic acid. A Waters Symmetry C8 $3.5 \mu \mathrm{m}, 2.1 \times 50 \mathrm{~mm}$ column (Waters Corporation, Milford, MA, USA) was used at a flow rate of 0.3 $\mathrm{ml} /$ minute. The analytical gradient profile was as follows (minute/\% of B): 0/5, 1/5, 6/50, 9/50, 11/5, 14/5, total run time 14 minutes. The typical injection volume was $10 \mu \mathrm{l}$. Mass spectrometry was performed on an API 4000 QTRAP $^{\mathrm{rm}}$ LC-MS/MS system fitted with a 

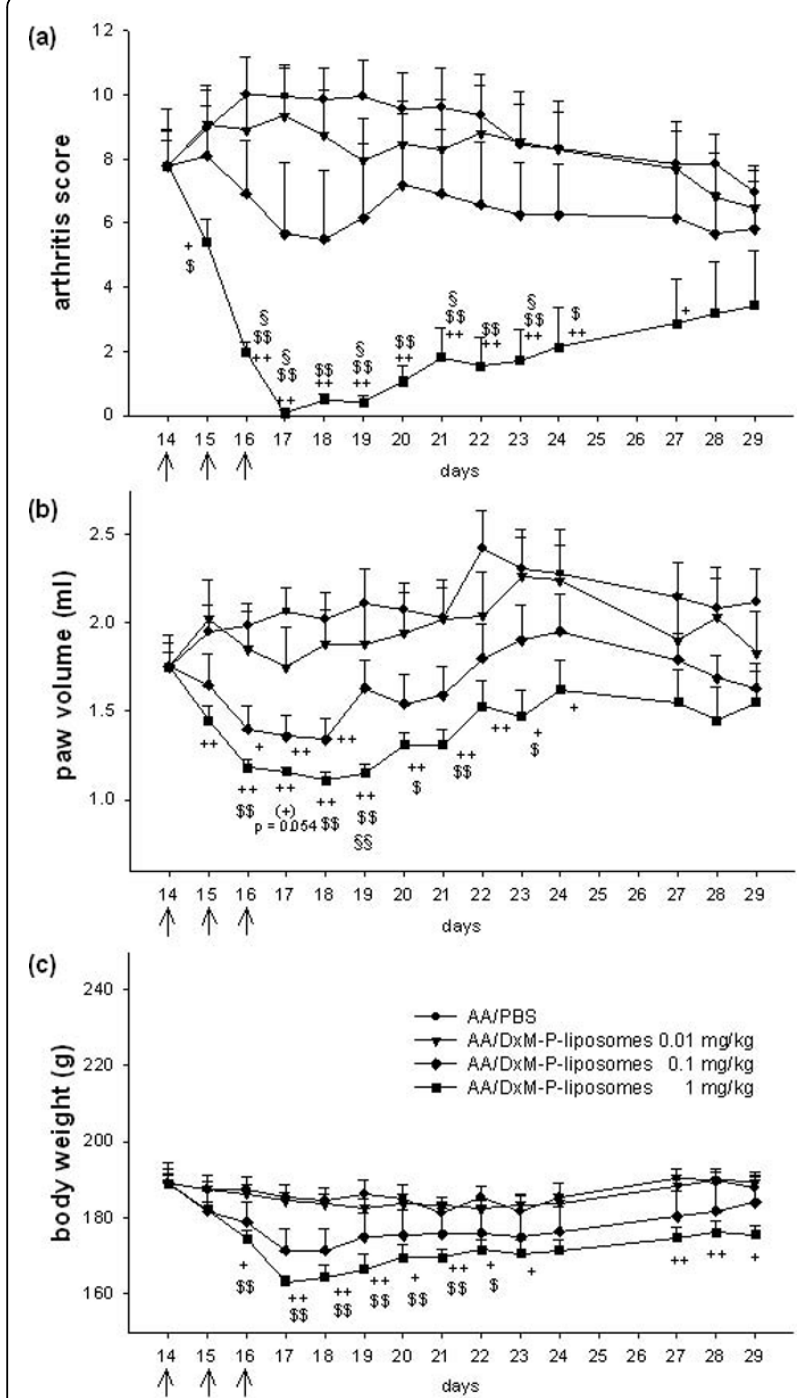

Figure 2 Dose-dependence of liposomal DxM-P in adjuvant arthritis (Experiment 4). (a-c): Dose-response of treatment with liposomal DxM-P $(3 \times 1 \mathrm{mg} / \mathrm{kg}, 3 \times 0.1 \mathrm{mg} / \mathrm{kg}$, or $3 \times 0.01 \mathrm{mg} / \mathrm{kg})$; all groups were normalized to the same mean value for each parameter on Day 14 ( $n=6$ each). $+P \leq 0.05,++P \leq 0.01 \mathrm{vs}$. AA/ PBS; $\$ P \leq 0.05, \$ \$ P \leq 0.01$ vs. AA/DxM-P-liposomes $0.01 \mathrm{mg} / \mathrm{kg} ; \S$ $P \leq 0.05$, $\S \S P 0.01$ vs. AA/DxM-P-liposomes $0.1 \mathrm{mg} / \mathrm{kg}$, * $P \leq 0.05$ vs. AA/DxM-P $1 \mathrm{mg} / \mathrm{kg}$; all Mann Whitney U-test. $\uparrow$ administration of PBS or liposomal DxM-P.

TurboIonSpray source and a hybrid triple quadrupole/ linear ion trap mass spectrometer (Applied Biosystems, Concord, ON, Canada). The instrument was operated in positive ion mode with an IonSpray voltage of $5500 \mathrm{~V}$, a source temperature of $550^{\circ} \mathrm{C}$, curtain gas (nitrogen) at 20 , collision gas (nitrogen) at 5 , ION source gas 1 (air) at 40 and Ion source gas 2 (air) at 45 (all arbitrary units). Quantification was performed in the MRM positive mode. For the detection of DxM (MW: 392.5), the transitions of $\mathrm{m} / z 393.6 \rightarrow 373.4, \mathrm{~m} / z 393.6 \rightarrow 355.5$ and $393.6 \rightarrow 337.4$ were optimized by adjustments of collision energy, declustering potential and dwell time. IS (prednisolone MW: 360.4) was monitored using the MRM transition of $m / z 361.6 \rightarrow 343.3$. The lower limit of quantification was $2.0 \mathrm{ng} / \mathrm{ml}$ in plasma and $2.5 \mathrm{ng} / \mathrm{g}$ in tissue.

The analytical procedure focussed on rigorous and validated quantification of DxM as the pharmacologically relevant analyte. In selected spleen samples, DxM$P$ detection was also accomplished in the negative ionization mode following assessment of: i) selectivity of the analysis for DxM and DxM-P; and ii) autosampler stability.

\section{Statistics}

Differences among groups were analyzed using the Mann Whitney U-Test $(P \leq 0.05)$, correlations among variables using the Spearman rank correlation (both SPSS 13.0 ${ }^{\mathrm{m}}$; SPSS Inc.; Chicago, IL, USA).

\section{Results}

\section{Clinical effects of Micromethason therapy in AA}

Short term i.v. treatment of established AA with liposomal DxM-P on Days 14, 15 and $16(3 \times 1 \mathrm{mg} / \mathrm{kg}$ body weight) resulted in a strong, significant, and long-lasting suppression of arthritis score and paw volume to almost normal levels (Figure 1a, b; Table 1). On Day 28, that is, two weeks after the initiation of treatment, liposomal DxM-P still reduced the arthritis score by $54 \%$ and the paw volume by $73 \%$ (Table 1). Despite a significant, but transient drop of the body weight after therapy with liposomal DxM-P (Figure 1c), the treatment was well tolerated by the rats, which showed an active and mobile behavior from Day 15 onwards. In contrast, the same dosage of free DxM-P $(3 \times 1 \mathrm{mg} / \mathrm{kg})$ only transiently reduced the arthritis score by $51 \%$ and the paw volume by $65 \%$, with a strong rebound starting two days after the end of therapy (Figure 1a, b; Table 1). PBSliposomes were ineffective or even induced a transient, numerical increase of the clinical signs (Figure 1a, b; Table 1).

Similar results were obtained in two independent repeats (Table 1; Experiments $2 / 3$ and Table 2; Experiment 4), confirming the validity of the data.

Interestingly, reduction of the area under the curve (AUC from Day 0 to Day 30) by liposomal DxM-P reached almost $54 \%$ for the arthritis score $(P \leq 0.05$; $19 \%$ with free DxM-P) and $74 \%$ for the paw swelling $(P \leq 0.05 ; 36 \%$ with free DxM-P; see inserts in Figure 1a, b).

\section{Dose-response experiments}

The effects of liposomal DxM-P were dose-dependent (Figure 2a-c; Table 2), that is, inhibition of arthritis 
score and paw swelling was significantly stronger after administration of high-dose liposomal DxM-P than after low-dose and medium-dose liposomal DxM-P (Figure 2a, b; Table 2).

Efficacy differences between liposomal and free DxM$\mathrm{P}$ were dose-dependently potentiated. Compared to free DxM-P, the reduction of the arthritis score on Day 19 was $10 \%$ higher with low-dose liposomal DxM-P, 13\% higher with medium-dose DxM-P, and 27\% higher with high-dose DxM-P (Table 2). The differences between high-dose liposomal DxM-P and high-dose free DxM-P were significant for the reduction of arthritis score $(P \leq$ 0.05 , Days 16 to 19$)$, paw volume $(P \leq 0.05$, Day 18$)$, but also the reduction of body weight $(P \leq 0.05$, Days 17 and 18; data not shown).

\section{Single-dose liposomal DxM-P}

Single-dose therapy with liposomal DxM-P $(1 \mathrm{mg} / \mathrm{kg})$ on Day 14 caused a significant, but short-lasting reduction of arthritis score $(P \leq 0.05$ vs. AA/PBS on Day 15; $P \leq$ 0.08 on Days 16 and 17$)$ and paw volume $(P \leq 0.05$ vs. AA/PBS on Day 15; $P \leq 0.06$ on Days 16, 17 and 19; data not shown). The magnitude of the effects on Days 19 and 29 were similar or even superior to those after therapy with three $\times$ free DxM-P in the same experimental group of animals $(1 \mathrm{mg} / \mathrm{kg}$; Table 1 ; experimental subgroups named Experiment 2 and 3).

In all groups, the paw volume on Day 19 showed a significant, positive correlation with the volume before treatment (Day 14; $P \leq 0.005$, rs $\geq 0.87 ; n=30$; Figure $3)$. The regression line gradient for rats treated three $x$ with high-dose liposomal DxM-P was $\mathrm{k}=0.33$, whereas that for PBS-treated rats was 1.26. These results show that three $\times$ administration of liposomal DxM-P strongly controlled the swelling even in the case of established, severe AA. The regression line gradient of three $\times$ treatment with liposomal DxM-P was smaller than that of one $\times$ treatment with liposomal DxM-P, indicating the dose-dependent effect on arthritis. Rats treated one $x$ with liposomal DxM-P or three $\times$ with free DxM-P showed similar gradients $(k=0.9$ and 0.86 , respectively) and thus comparable therapeutic efficacy (Figure 3).

\section{Histological results}

On Day 21, untreated arthritic animals showed massive infiltration with acute/chronic inflammatory cells and synovial hyperplasia, as well as marked loss of bone and cartilage (Figure 4c). Both free DxM-P and liposomal DxM-P significantly inhibited acute granulocytic inflammation and joint destruction, although some chronic infiltration of mononuclear cells, synovial hyperplasia, and deformation persisted (Figure 4a, e-f). Signs of chronic and especially acute inflammation were reduced

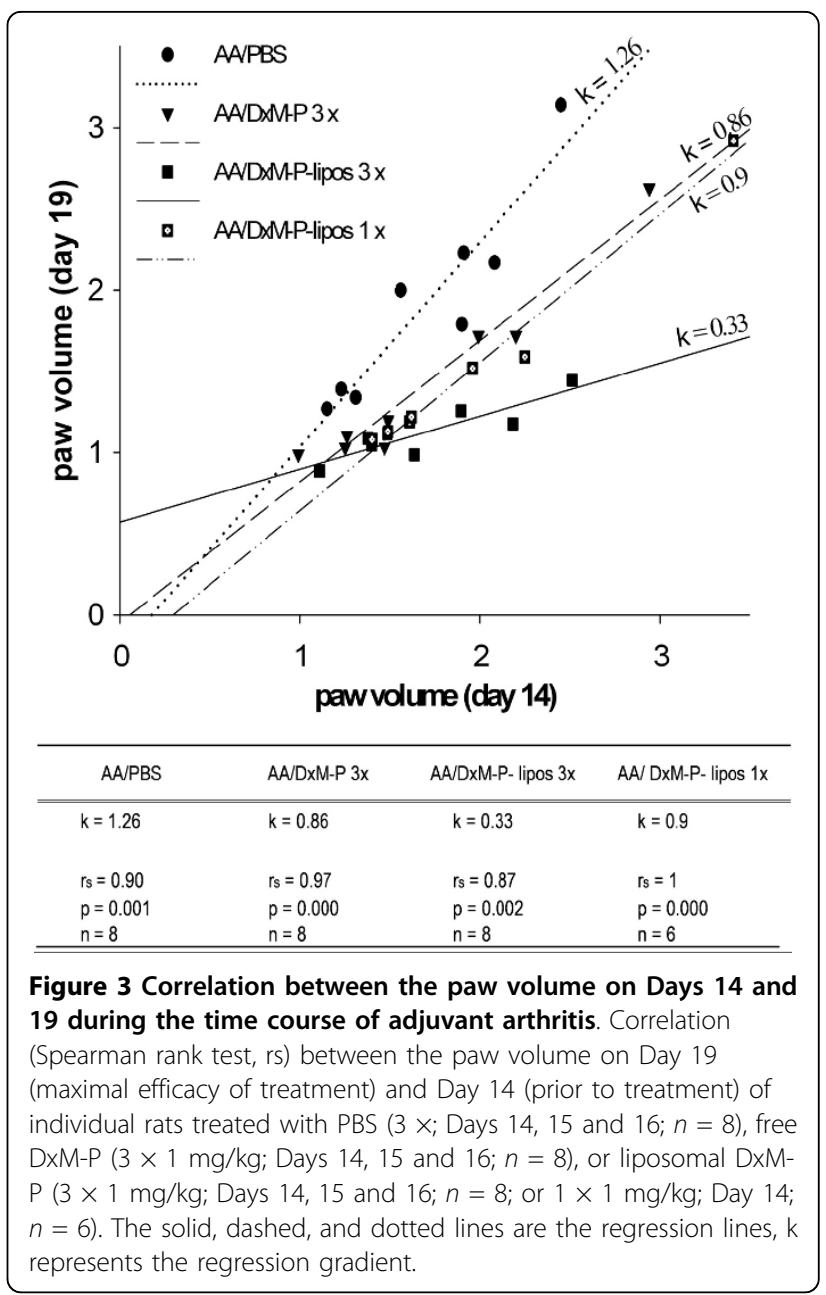

to a somewhat greater extent by liposomal than by free DxM (data not shown).

\section{Hematological results}

ESR

Only liposomal DxM-P treatment $(3 \times 1 \mathrm{mg} / \mathrm{kg})$ significantly reduced the ESR $(60 \%$ and $65 \%$ reduction, respectively, vs. AA/PBS or AA/PBS-liposomes; Figure 5a).

\section{Total and differential WBC}

AA rats treated with free DxM-P showed only a partially decreased (20 to 30\%) leukocytosis compared to AA/ PBS (Figure 5b). In contrast, liposomal DxM-P completely reversed the leukocytosis observed in untreated AA, showing a WBC count similar to that of healthy controls $(P \leq 0.01$; significantly stronger inhibition than that achieved by PBS-liposomes, $P \leq 0.05$ ).

Untreated AA was characterized by a significant, relative neutrophilia (increase of polymorphonuclear neutrophilic leukocytes (PMN) from 19 to $48 \%$ ) and a relative lymphopenia (decrease of lymphocytes from 77 to $48 \%$; Figure 5c). PBS-liposomes had no effect on PMN or 


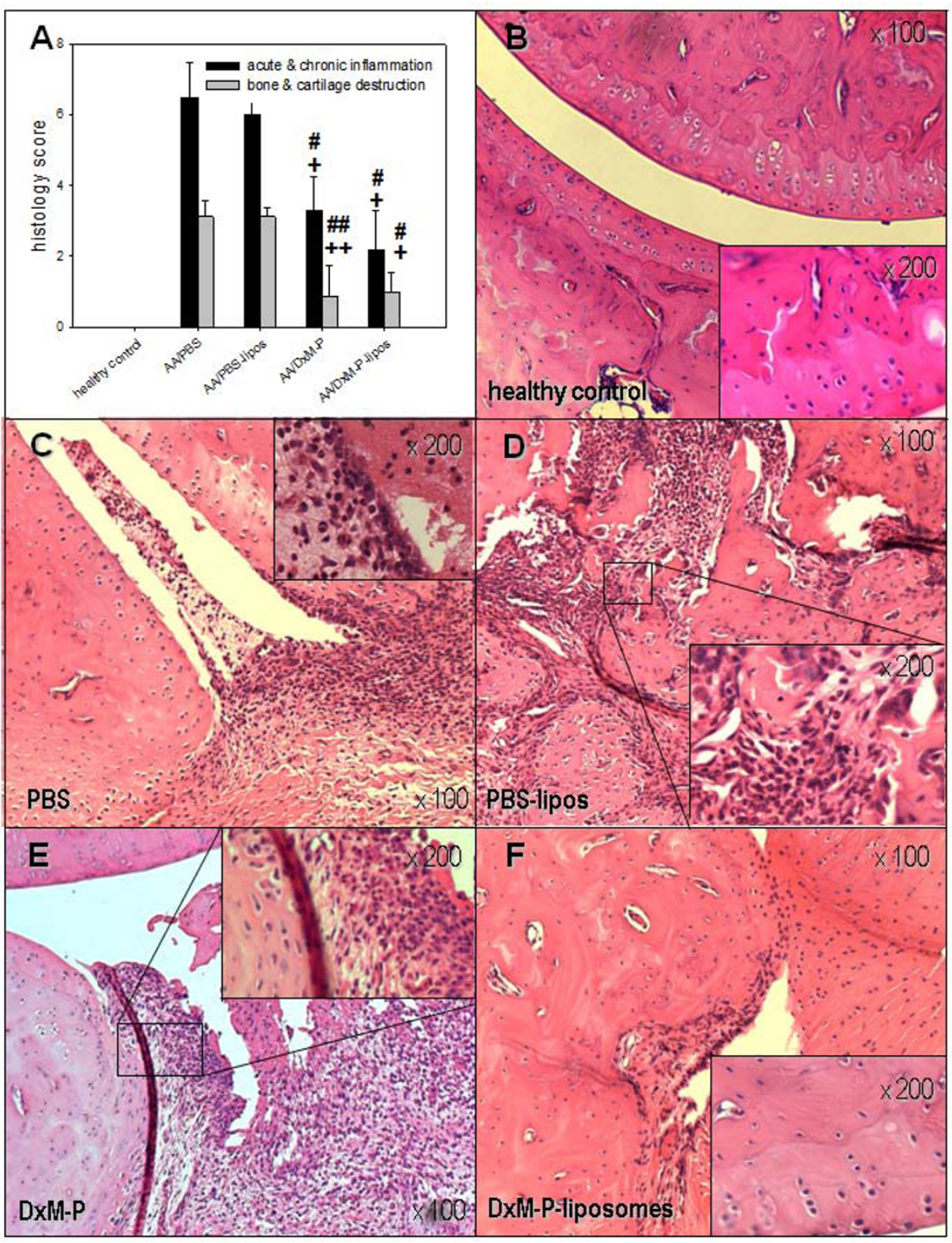

Figure 4 Histological effects of liposomal DxM-P in adjuvant arthritis (Day 21; Experiment 2/3). Inflammation and destruction score (a) and images of HE-stained joints sections from healthy controls (b) or arthritic rats after treatment with PBS (c), PBS-liposomes (d), free DxM-P (e), or liposomal DxM-P (f) (for details see Figure 1). $+P \leq 0.05,++P \leq 0.01$ vs. AA/PBS; \# $P \leq 0.05$, \#\# $P \leq 0.01$ vs. AA/PBS-liposomes; all Mann Whitney U-test.

lymphocyte count. The absolute number of PMN was significantly decreased by liposomal DxM-P $(P \leq 0.05$ vs. AA/PBS; Figure 5d), but not by free DxM-P. Despite their clear therapeutic efficacy, however, both free DxM$\mathrm{P}$ and liposomal DxM-P led to a further, significant decrease of absolute and relative lymphocyte counts (decrease to $33 \%$ and $29 \%$, respectively; Figure 5c, d) and to an increase of the percentages of PMN (increase to $57 \%$ and $64 \%$, respectively).

The relative reduction of lymphocytes and the relative increase of PMN were more prominent with liposomal
DxM-P than with free DxM-P. The lymphocyte percentage was significantly lower (the PMN percentage higher) after free DxM-P or liposomal DxM-P than in PBS-treated AA rats (Figure 5c).

\section{Immune status}

\section{Delayed-type hypersensitivity}

Little reaction was observed after i.d. injection of $\mathrm{Mb}$ solution in the ear. Only AA rats treated with liposomal DxM-P showed a significantly higher DTH than healthy or arthritic controls $(P \leq 0.05$; Figure $5 \mathrm{e})$. 

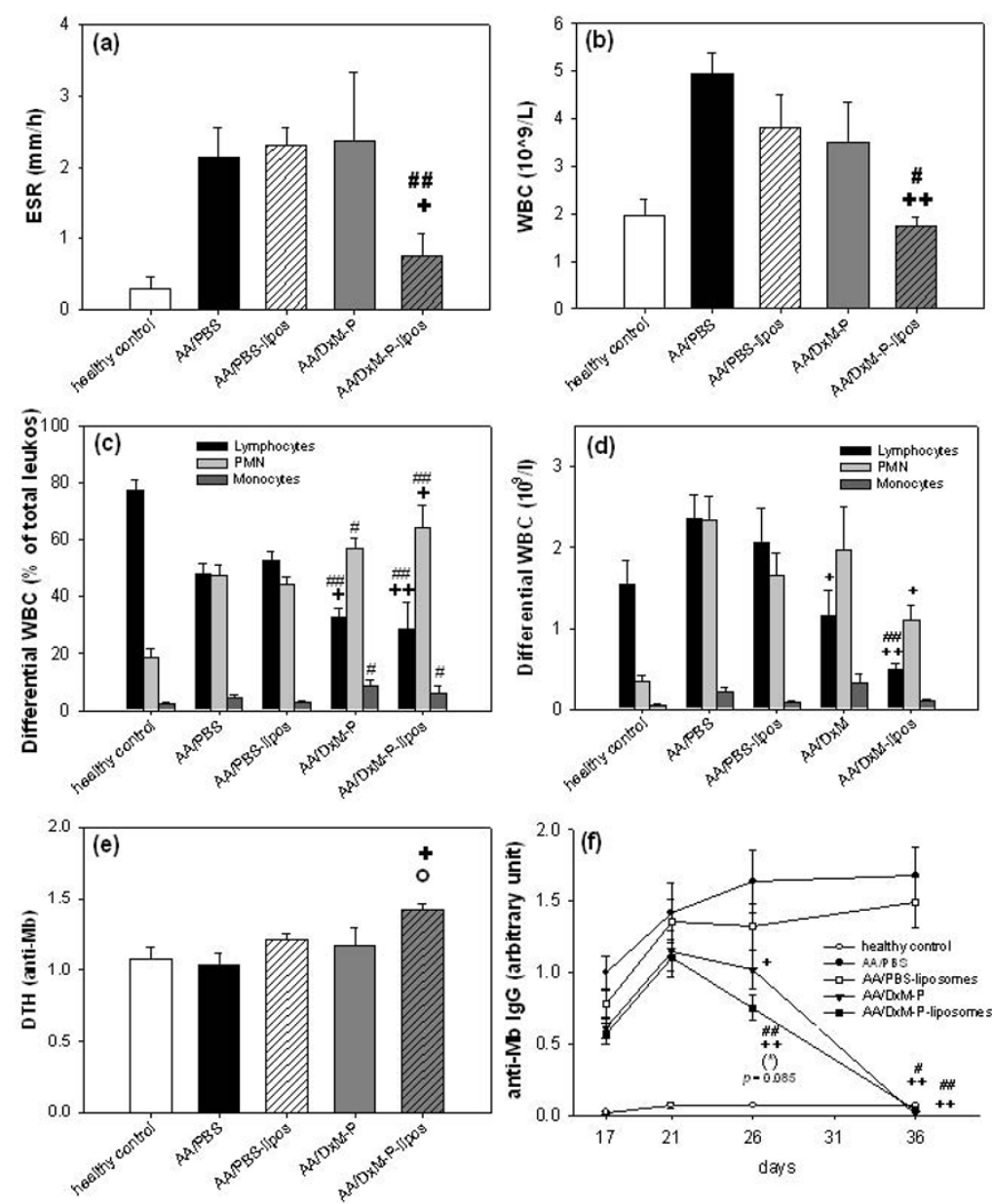

Figure 5 Hematological parameters (Day 21) and anti-Mb IgG response (Days 17 to 36) in adjuvant arthritis (Experiment 2/3) Erythrocyte sedimentation rate (ESR) (a), white blood cell count (WBC) (b), differential WBC in relative percentages (c) and absolute numbers of leukocytes (d), delayed type hypersensitivity (DTH) (e), and time course of serum anti-Mb lgG (f) after treatment as in Figure $1 ; n=8$ for all groups. $+P \leq 0.05,++P \leq 0.01$ vs. AA/PBS; $\# P \leq 0.05$, \#\# $P \leq 0.01$ vs. AA/PBS-liposomes; $\left({ }^{*}\right) P \leq 0.085$ vs. AA/DxM-P; all Mann Whitney U-test.

\section{Anti-Mb IgG in serum}

The levels of anti-Mb IgG were significantly reduced by liposomal DxM-P from Day 26 onwards, reaching healthy control levels on Day 36 (Figure 5f). No significant differences were observed between liposomal DxM$P$ and free DxM-P, although the decrease of serum antiMb IgG was somewhat more rapid after liposomal DxM-P therapy (Figure 5f).

\section{Blood lymphocytes}

Free and liposomal DxM-P significantly reduced the number of circulating lymphocytes, in the case of liposomal DxM-P down to $0.49 \times 10^{9}$ cells/L (Figure 6a).

\section{Spleen lymphocytes}

In AA rats, liposomal DxM-P significantly reduced the lymphocyte numbers in the spleen to healthy control values $\left(44 \times 10^{6}\right.$ cells), whereas free DxM-P and PBSliposomes had no significant effect on the lymphocyte infiltration (Figure 6b).

\section{Pop LN lymphocytes}

Only liposomal DxM-P counteracted the lymphocyte infiltration in the pop LN, leading to numbers below those of healthy controls $\left(0.25 \times 10^{6}\right.$ cells; Figure $\left.6 \mathrm{c}\right)$. Free DxM-P had no effect.

\section{Cytokine production by peritoneal $\mathrm{M} \varphi$ (PM)}

In non-stimulated PM (Figure 7a) or stimulated PM (Figure $7 \mathrm{~b}-\mathrm{d}$ ), the cytokine production did not significantly differ between healthy and PBS-treated AA rats (data only shown for IL-6).

\section{IL-6}

In non-stimulated PM, previous in vivo treatment with PBS-liposomes or liposomal DxM-P significantly reduced the IL-6 production (Figure 7a). In contrast, in LPS-stimulated PM, only liposomal DxM-P significantly reduced the IL-6 production. These effects were significantly stronger than those observed with free DxM-P (Figure 7b). 

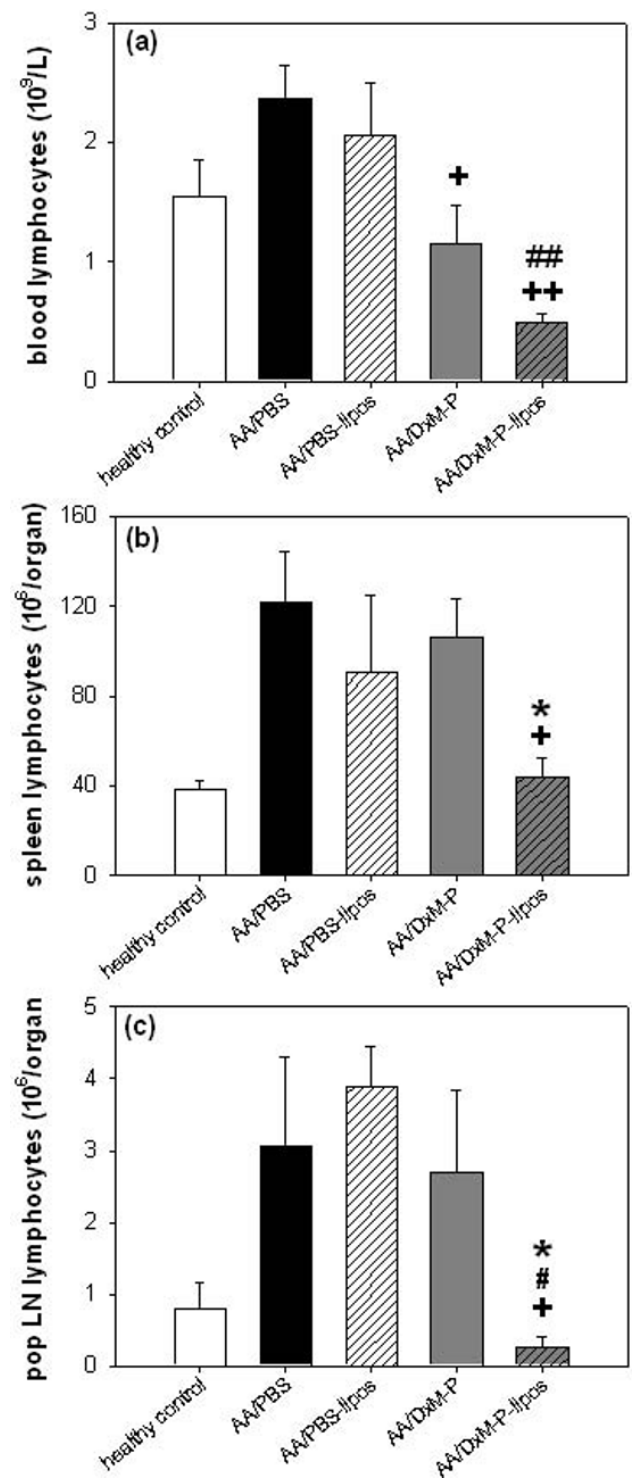

Figure 6 Effects of liposomal DxM-P on lymphocytes in adjuvant arthritis (Day 21; Experiment 2/3). Assessment of lymphocytes in blood (a) $(n=8)$, spleen (b) $(n=4)$ and pop LN (c) $(n=4)$ after treatment with PBS, PBS-liposomes, free DxM-P, or liposomal DxM-P (for details see Figure 1). $+P \leq 0.05,++P \leq 0.01$ vs. AA/PBS; \# $P \leq 0.05$, \#\# $P \leq 0.01$ vs. PBS-liposomes; ${ }^{*} P \leq 0.05$ vs. AA/DxM-P; all Mann Whitney U-test.

\section{$T N F-\alpha$}

No effects of any in vivo therapy on TNF- $\alpha$ secretion were observed in non-stimulated PM (data not shown) or LPS-stimulated PM (Figure 7c).

IL-1 $\beta$

No significant effects were observed in non-stimulated PM (data not shown). IL-1 $\beta$ secretion in LPS-stimulated $\mathrm{PM}$ was significantly reduced by in vivo treatment with PBS-liposomes or liposomal DxM-P (Figure 7d; free DxM-P failed to reach statistical significance).

\section{Pharmacokinetics/biodistribution of DxM}

DxM was measured as the pharmacologically relevant species in plasma and tissues, since the pro-drug DxM$\mathrm{P}$ is rapidly converted in body fluids.

\section{Plasma}

DxM concentrations in the circulating blood rapidly decreased within the first 24 hours after injection of either liposomal or free DxM-P. However, plasma concentrations following the injection of liposomal DxM-P remained above $20 \mathrm{ng} / \mathrm{mL}(50 \mathrm{nM})$ throughout the 96 hours time point, significantly higher than those after injection of free DxM-P (approximately 2.8-fold at 0.5 hours; 17.7 -fold at 24 hours; 14 -fold at 72 hours, and $\geq 10$-fold at 96 hours; all $P<0.01$; Figure $8 \mathrm{a}$ ).

\section{Synovial membrane, spleen, and liver}

No DxM was detectable in the synovial membrane of AA rats treated with free DxM-P at any time point investigated, while use of liposomal drug resulted in deposition of DxM at 72 hours and 96 hours (Figure $8 \mathrm{~b})$. Also, DxM concentrations in both spleen and liver were significantly higher 72 hours and 96 hours after treatment with liposomal DxM-P $(P<0.05$, Figure 8c, d).

After 288 hours (nine days), the levels of DxM in almost all of the samples were below the quantification limit (2.0 ng/ml in plasma or $2.5 \mathrm{ng} / \mathrm{g}$ in tissues).

The present pharmacokinetic analysis focused on absolute concentrations of DxM as the pharmacologically relevant analyte. However, in selected spleen samples, DxM-P was also detected using a modification of the analytical procedure ( $\mathrm{LC}$ followed by detection in the negative ionization mode). DxM-P in the spleen showed average levels of approximately $100 \mathrm{ng} / \mathrm{g}$ and 10 ng/g tissue at 72 hours and 96 hours, respectively, following injection of liposomal DxM-P, that is, similar to those of the corresponding DxM.

\section{Discussion}

Intravenous therapy with liposomal DxM-P in established AA (analogous to the clinical situation in RA) suppressed joint swelling and inflammation in a significant, dose-dependent, and long-lasting manner. Notably, liposomal DxM-P showed superior therapeutic efficacy in both early and advanced disease compared to matched doses of free DxM-P. Liposomal encapsulation, therefore, clearly potentiates the clinical efficacy of the well-established anti-rheumatic glucocorticoid (GC) DxM-P.

This superior efficacy is already achieved upon shortterm treatment for three days, similar to successful, long-term suppression of human RA [37] and rat antigen-induced arthritis (including an approximately $80 \%$ reduction of a flare-up induced seven days after the end of treatment) [19]. The prolonged efficacy may represent 

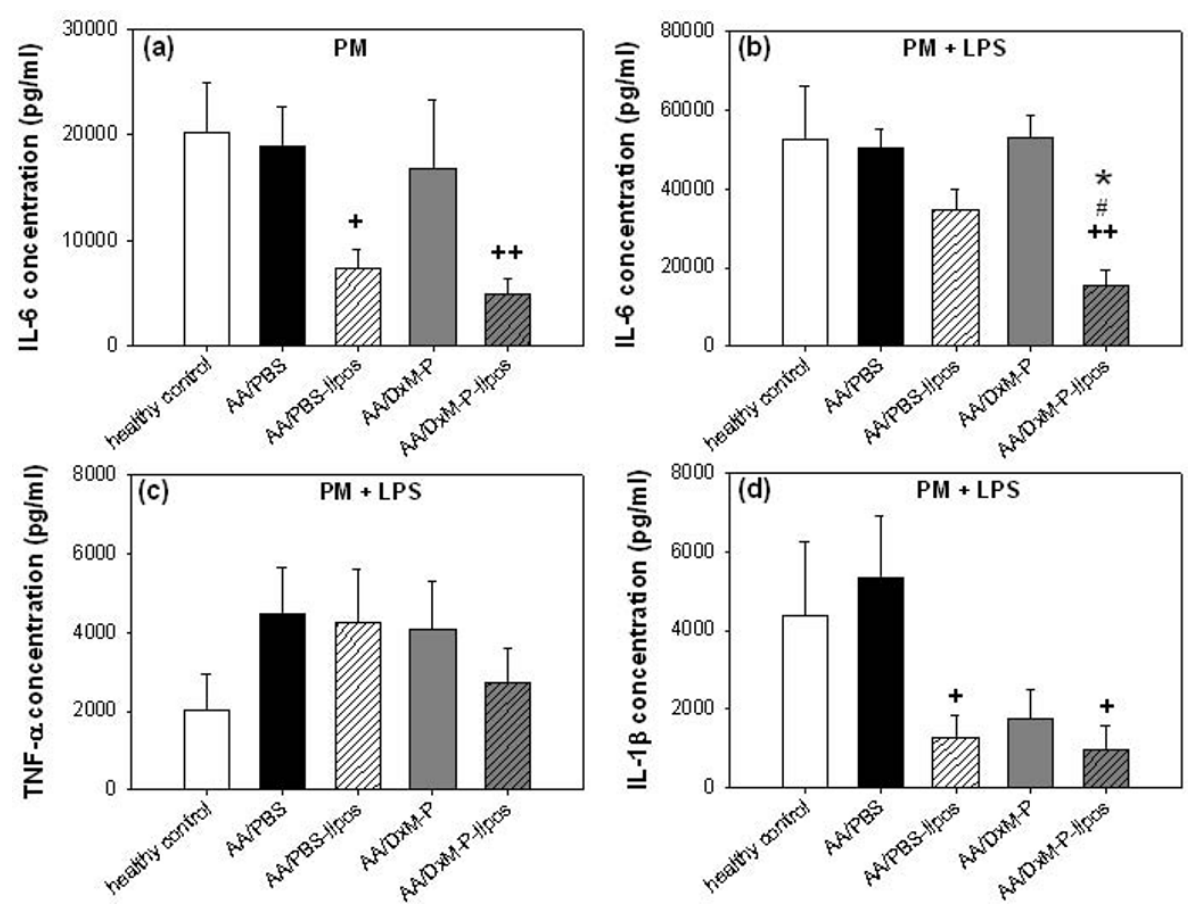

Figure 7 Cytokine production by peritoneal $M \varphi$ in adjuvant arthritis (Day 21; Experiment 2/3). IL-6 (a-b), TNF- $\alpha$ (c), and IL-1 $\beta$ (d) production by non-stimulated and LPS-stimulated peritoneal $\mathrm{M \varphi}$ after treatment as in Figure $1 ; n=4$ for all groups. $+P \leq 0.05,++P \leq 0.01 \mathrm{vs}$. AA/PBS; \# $P \leq 0.05$ vs. AA/PBS-liposomes; * $P \leq 0.05$ vs. AA/DxM-P; all Mann Whitney U-test.

a substantial advantage in the treatment of RA, with the potential to obtain therapeutic effects with lower and/or less frequent doses. Of interest, the AUC for arthritis score/paw volume was more markedly reduced by liposomal than by free DxM-P, suggesting a decrease of the cumulative disease activity altogether.

Pharmacokinetic/biodistribution results showed a slower elimination of the liposomal drug from the circulation, confirming previous results [38], and substantially higher levels and longer persistence of the liposomal form of the drug in synovial membrane, spleen and liver until at least 48 hours after the last injection. These depot effects likely contribute to the superior and prolonged clinical efficacy of the encapsulated formulation. Enhanced therapeutic efficacy extended until Day 9 post injection of the first dose (corresponding to Day 23 of AA; Figure 1), although no DxM was detectable in blood or synovial tissue at this time point. Typical GCreceptor mediated drug actions require $1 \mathrm{nM}$ concentrations or less of DxM, a level that is below the quantification limit of $5 \mathrm{nM}(2 \mathrm{ng} / \mathrm{ml})$ of the LC-MS method employed. Residual liposomal drugs in circulation and/ or tissues may thus contribute to the persistence of clinical effects [19].

In an independent arthritis study, administration of one dose of liposomal DxM-P $(1 \mathrm{mg} / \mathrm{kg})$ and three doses of free DxM-P $(3 \times 1 \mathrm{mg} / \mathrm{kg})$ showed comparable therapeutic efficacy. In addition, long-term suppression of AA by three medium doses of liposomal DxM-P $(3 \times$ $0.1 \mathrm{mg} / \mathrm{kg}$ ) was basically equivalent to that of three high doses of free DxM-P $(3 \times 1 \mathrm{mg} / \mathrm{kg})$. Furthermore, blood DxM concentrations 24 hours after a single dose of liposomal administration $(1 \mathrm{mg} / \mathrm{kg})$ were 17 -fold and 5 -fold higher, respectively, than 24 hours after a single or triple administration of free drug (one or three doses of $1 \mathrm{mg} /$ $\mathrm{kg}$ ). Thus, the present results indicate that liposomal encapsulation allows a dose reduction by a factor of at least 3 , if not 10. Also, the difference between the clinical efficacy of matched doses of liposomal and free DxM-P was augmented with rising DxM-P concentrations, suggesting that potentiation by liposomal encapsulation may be enhanced by a higher dose of DxM-P.

Dose reductions via encapsulation have been recently described in AA with prednisolone-containing PEGylatedliposomes [22,23]. Avnir et al. [23] achieved an effective suppression of arthritis by administering two or three doses of $10 \mathrm{mg} / \mathrm{kg}$ methylpredisolone either in early AA (Days 10 and 14, or Days 10,14 and 18) or in established AA (Days 19 and 23) using PEGylated, remote-loaded liposomes. The latter results are very similar to those of the present study, in particular when considering the differences between methylprednisolone and DxM in terms of glucocorticoid equivalent. To our knowledge, however, this study provides the first evidence of a prolonged and 


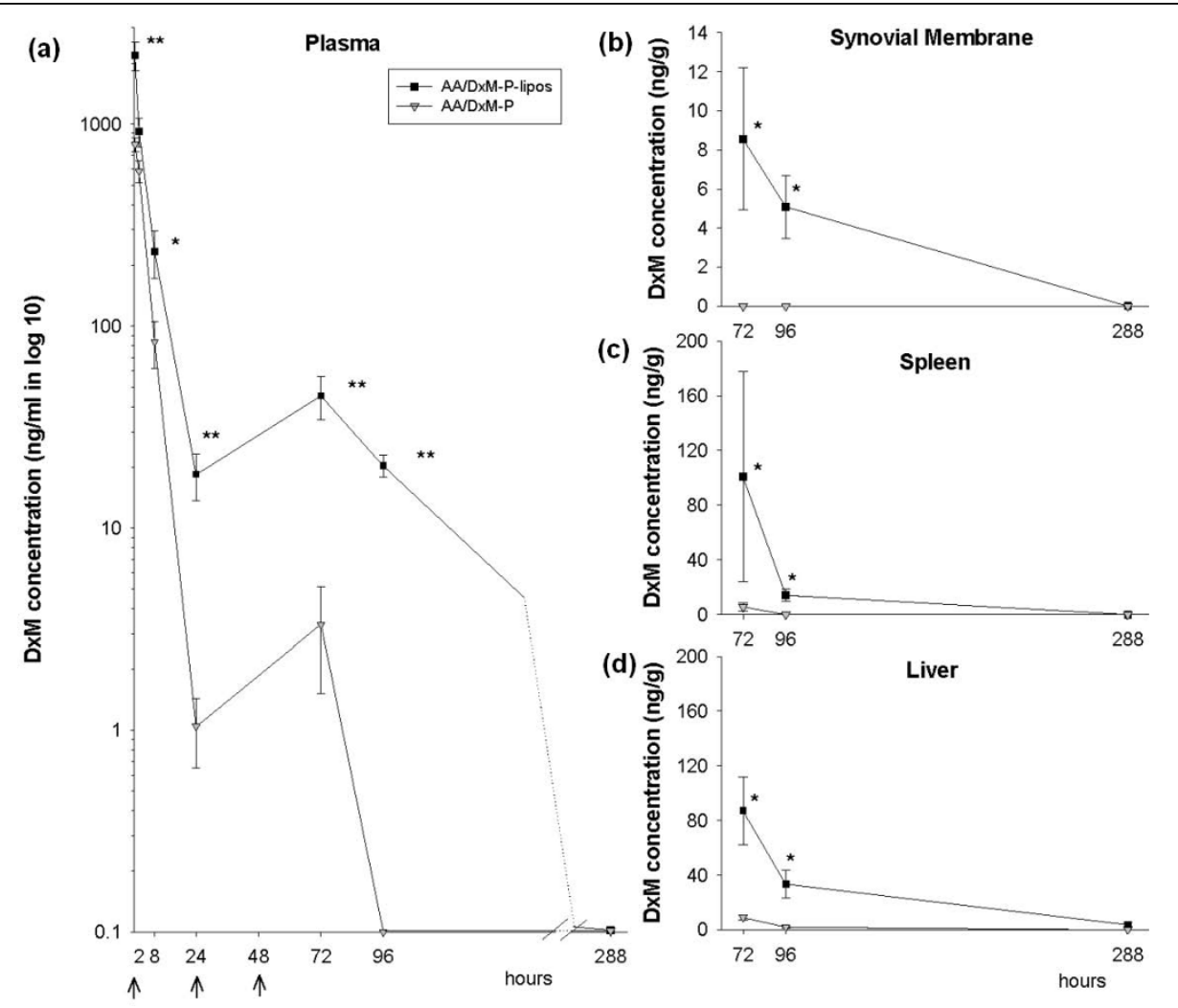

Figure 8 Biodistribution of free or liposomal DxM-P in adjuvant arthritis. Concentration of DxM in blood (a) $(n=6)$, synovial membrane (b) $(n=3)$, spleen (c) $(n=3)$, and liver (d) $(n=3)$ at $0.5,2,8,24$, and/or 72, 96, and 288 hours after the initial i. v. treatment with free or liposomal DxM-P during the time course of AA (for details see Figure 1). ${ }^{*} P \leq 0.05,{ }^{* *} P \leq 0.01$ vs. AA/DxM-P; all Mann Whitney U-test; administration of free or liposomal DxM-P at the time points 0 hours, 24 hours, and 48 hours.

nearly $100 \%$ remission in severe established AA with DxM-P in non-PEGylated liposomes.

The long-term benefit of short-term therapy with liposomal DxM-P was histologically confirmed by significant reduction of inflammation, as well as bone and cartilage destruction. At this relatively early stage of disease (Day 21 ), the histological effects of free DxM-P were similar to those of liposomal DxM-P, and did not yet reflect the clinical rebound observed with free DxM-P after Day 19. Interestingly, only liposomal DxM-P accumulated in the inflamed synovial membrane, matching the targeting of the inflamed joint achieved by other novel liposome formulations [23]. Based on the known direct and indirect contribution of synovial $\mathrm{M} \varphi$ to cartilage and bone destruction via TNF- $\alpha$, IL-1 $\beta$, or IL- $6[2,3,7,39]$, the present histological findings suggest that both $\mathrm{M} \varphi$ activation and secretion of pro-inflammatory mediators are inhibited by effectively targeting these cells with liposomal DxM-P. Local efficacy of liposomal DxM-P extended to periarticular tissue (data not shown) and pop LN, in which liposomal (but not free) DxM-P reduced the number of lymphocytes presumably involved in regional perpetuation of inflammation [40].
The present study demonstrates for the first time that, in contrast to free DxM-P, i.v.-injected liposomal DxM$P$ showed systemic anti-inflammatory effects by profoundly decreasing ESR and total WBC during acute and chronic AA. Although leukocytosis in PBS-treated AA was already paralleled by an increase of the relative percentage of PMN and a reduction of the lymphocyte percentage, both free DxM-P and liposomal DxM-P caused a further significant decrease of circulating lymphocytes. Lymphocytes were reduced to levels below $50 \%$ and $75 \%$ of those in healthy controls by both free and liposomal DxM-P, respectively, suggesting that lymphopenia may be the result of direct DxM effects in addition to indirect effects via $\mathrm{M} \varphi$ inactivation.

Free GCs, in particular DxM-P, are known to diminish the number of circulating lymphocytes via two mechanisms [41]: 1) redistribution to spleen, lymph nodes, bone marrow, and perivascular compartments; 2) induction of cell apoptosis. In the present study, however, significantly lower numbers of lymphocytes in lymphoid organs were observed after therapy with liposomal DxM-P, suggesting that redistribution to spleen and LN either did not occur or was balanced by increased local 
lymphocyte apoptosis. Since liposomes are hardly taken up by lymphocytes in vitro ([42] and own results, data not shown), direct induction of lymphocyte apoptosis by liposomal DxM-P is unlikely. Thus, the specific contribution of the prolonged accumulation of liposomal DxM in the spleen to systemic lymphocyte redistribution remains to be analyzed.

It is presently unclear whether the therapeutic efficacy of liposomal DxM-P is due to sustained immunosuppression. On one hand, the DTH to pathogenetic Mb was significantly increased on Day 21 after liposomal DxM-P treatment when compared to AA/PBS, which speaks against immunosuppression. This may indicate a shift of the Th1/Th2 balance $[40,43]$ in favor of a protective $\mathrm{T}$ cell reactivity, for example by modulating the $\mathrm{M} \varphi$ cytokine pattern [44] and/or by inducing a regulatory Th1 type DTH [45]. On the other hand, liposomal (but also free) DxM-P completely reverted the pathologically increased levels of specific serum anti-Mb IgG after Day 21; thus, the therapeutic effect of liposomal DxM-P may at least be partially due to, or associated with, effects on humoral immunity. However, since total IgG was not evaluated, it remains unclear whether this represents broad suppression of the humoral immune response or rather selective inhibition of disease-triggered immunity. The delay of the effects on the specific IgG levels compared to those on the cell-mediated immunity is likely due to the long half-life of the circulating IgG.

$\mathrm{M} \varphi$ were clearly addressed by the liposomal DxM-P, as shown by a significant, persistent inhibition of the secretion of pro-inflammatory cytokines in peritoneal $M \varphi$ (until five days after the end of therapy). At this point in time, liposomal DxM-P had little effect on TNF- $\alpha$ secretion by peritoneal $M \varphi$, suggesting that, if these results are transferable to the arthritic joints [40], clinical improvement may not be primarily mediated by local reduction of TNF- $\alpha$, but rather by reduction of IL$1 \beta$ and IL-6.

As described above, clinical efficacy of liposomal DxM-P may be related to its prolonged circulation in the blood and its enhanced accumulation in the affected joint; however, marked accumulation in other immunologically active organs (spleen and liver) is also likely to influence AA on a local and systemic level. A similar marked accumulation was observed in the spleen of AIA rats following injection of our liposomal DxM-P [19]; thus, the spleen may represent a key efficacy target of these novel liposomes, in line with the known contribution of the spleen to inflammation severity in acute AA [40]. On the other hand, liver acumulation may reduce the number of activated macrophages in the liver and thereby suppress the subsequent local production of pro-inflammatory cytokines such as IL-1 $\beta$ [46].
However, in addition to local and systemic depot effects of liposomal DxM, also non-genomic effects of high DxM peak levels may contribute to its therapeutic efficacy [38].

The administration of three doses of $1 \mathrm{mg} / \mathrm{kg}$ liposomal DxM-P transiently reduced the body weight. This is a known, rat-specific side-effect of glucocorticoids (observed at doses above $0.05 \mathrm{mg} / \mathrm{kg}$ DxM), mediated by decreased ribosomal amino acid incorporation into muscle cells [47], and possibly related to low plasma levels of released DxM-P [20]. Thus, lymphopenia (see above) and body weight reduction appeared to be the only evident side-effects of treatment. Of note, higher drug adsorption of liposomal DXM-P in tissues and organs is not associated with stronger GC side effects. Instead, triggering of the HPA axis, gluconeogenesis or lymphocyte alterations are markedly reduced in comparison with the effects of free DxM-P [38].

Drug-free liposomes showed a modest pro-inflammatory effect in acute and chronic AA (especially after Day 26). PEGylated liposome formulations are known to induce allergic reactions $[26,48]$, possibly as a result of complement activation [49]. However, liposome size (especially above $90 \mathrm{~nm}$ ) can also play a key role in complement activation [50], potentially explaining the slightly increased lymphocyte number in pop LN observed with the non-PEGylated PBS-liposomes in our study (mean size $300 \mathrm{~nm}$ ). Pro-inflammatory effects in the arthritic joint, in turn, may be due to increased liposome uptake by activated $\mathrm{M} \varphi$, possibly triggered by lysosomal degradation of DPPC to lyso-phosphatidylcholine, which significantly increases $M \varphi$ ingestion [51]. Recent improvements such as the increase of the drug-to-lipid ratio may allow diminishing the lipid load [23].

\section{Conclusions}

The present investigation on this M $\varphi$-targeting formulation is a good example of translational research and shows that encapsulation of potent anti-inflammatory steroids has the potential to enhance/prolong therapeutic efficacy and limit side-effects. This preparation may therefore be suitable to obtain long-lasting effects with lower or less frequent dosages of GC in non-immunogenic drug carriers for the treatment of human diseases such as RA. Depot and/or recirculation effects in plasma, inflamed joint, liver, and spleen may contribute to the enhanced efficacy of liposomally encapsulated DxM-P.

\section{Abbreviations}

AA: adjuvant arthritis; ACCN: acetonitrile; Ab: antibody; AUC: area under the curve; DMARD: disease modifying anti-rheumatic drug; DPPC: 1,2dipalmitoyl-sn-glycero-3-phosphocholine; DPPG: 1,2-dipalmitoyl-sn-glycero-3(phosphor-rac-(1-glycerol))(sodium salt); DTH: delayed type hypersensitivity; 
DXM-P: dexamethasone phosphate; ESI: electrospray ionization; ESR: erythrocyte sedimentation rate; FA: formic acid; GC: glucocorticoids; HE: haematoxilin \& eosin; HPLC: high performance liquid chromatography; i.d.: intradermal; IL: interleukin; Ig: immunoglobulins; IS: internal standard; i.v.: intravenous; LC: liquid chromatography; LPS: lipopolysaccharide; LN: lymph node; Mb: Mycobacterium butyricum; M $\varphi$ : macrophages; MS: mass spectrometry; PBS: phosphate-buffered saline; PEG: polyethyleneglykol; PM: peritoneal macrophages; PMN: polymorphonuclear neutrophilic leukocytes; RA: rheumatoid arthritis; TNF: tumor necrosis factor; WBC: white blood cell count.

\section{Acknowledgements}

A. González, S. Marín, and E. Ramiro, Department of Physiology, Faculty of Pharmacy, University of Barcelona are especially thanked for the collaboration in performing the experiments. R. Stöckigt and C. Hüttich, Institute of Pathology, and B. Ukena, Experimental Rheumatology Unit, Department of Orthopedics, University Hospital Jena, are gratefully acknowledged for technical assistance and Dr. E. Palombo-Kinne for critical revision of the manuscript.

The study was supported by the German Federal Ministry of Education and Research (BMBF; grant FKZ 010405 to R.W. Kinne, Interdisciplinary Center for Clinical Research (IZKF) Jena).

\section{Author details}

${ }^{1}$ Experimental Rheumatology Unit, Department of Orthopedics, University Hospital Jena, Klosterlausnitzer Str. 81, 07607 Eisenberg, Germany. 2Department of Physiology, Faculty of Pharmacy, University of Barcelona, Av. Joan XXIII s/n, 08028 Barcelona, Spain. ${ }^{3}$ Institute of Pathology, University Hospital Jena, Ziegelmühlenweg, 07743 Jena, Germany. ${ }^{4}$ Division of Pharmacology-Pharmacotechnology, Biomedical Research Foundation, Academy of Athens, Soranou Efesiou 4 street, 11527 Athens, Greece. ${ }^{5}$ novosom AG, Weinbergweg 22, 06120 Halle/Saale, Germany.

\section{Authors' contributions}

RA carried out the study, performed the statistical analysis and drafted the manuscript. AF, MC and FP participated in the design, coordination and execution of the in vivo studies. DP carried out the dose-response analysis and MG evaluated the histological slides. APS, TK, and CT designed, executed and described the pharmacokinetics/biodistribution experiments. RB coordinated dose response analysis, histological studies, and immunoglobulin ELISAs. SP and UR manufactured the liposomes and participated in the drafting of the manuscript. RWK initiated the study, participated in its design and coordination, and was the main contributor to the manuscript. All authors read and approved the final manuscript.

\section{Authors' information}

This study represents the first step of investigations carried out on this novel glucocorticoid formulation, in which its clinical efficacy has been proven. Molecular effects and mechanism of actions on $\mathrm{M} \varphi$ have also thoroughly been investigated in a separate series of in vitro experiments and are the subjects of a separate manuscript.

\section{Competing interests}

Steffen Panzner is founder and shareholder of Novosom AG. Novosom AG holds patent WO/2004/047792: Liposomal glucocorticoids, which is granted or pending in several jurisdictions. RB and RWK have each received a onetime compensation of $<10,000$ Euros as inventors.

Received: 28 June 2009 Revised: 13 June 2010 Accepted: 19 July 2010 Published: 19 July 2010

\section{References}

1. Firestein GS, Alvaro-Gracia JM, Maki R: Quantitative analysis of cytokine gene expression in rheumatoid arthritis. J Immunol 1990, 144:3347-3353.

2. Mulherin D, Fitzgerald O, Bresnihan B: Synovial tissue macrophage populations and articular damage in rheumatoid arthritis. Arthritis Rheum 1996, 39:115-124.

3. Kinne RW, Stuhlmüller B, Burmester GR: Cells of the synovium in rheumatoid arthritis. Macrophages. Arthritis Res Ther 2007, 9:224.

4. Schulze-Koops H, Davis LS, Kavanaugh AF, Lipsky PE: Elevated cytokine messenger RNA levels in the peripheral blood of patients with rheumatoid arthritis suggest different degrees of myeloid cell activation. Arthritis Rheum 1997, 40:639-647.

5. Bresnihan B: Pathogenesis of joint damage in rheumatoid arthritis. $J$ Rheumatol 1999, 26:717-719.

6. Koch AE, Polverini PJ, Kunkel SL, Harlow LA, DiPietro LA, Elner VM, Elner SG, Strieter RM: Interleukin-8 as a macrophage-derived mediator of angiogenesis. Science 1992, 258:1798-1801.

7. Scott BB, Weisbrot LM, Greenwood JD, Bogoch ER, Paige CJ, Keystone EC: Rheumatoid arthritis synovial fibroblast and U937 macrophage/ monocyte cell line interaction in cartilage degradation. Arthritis Rheum 1997, 40:490-498.

8. Genovese MC, Bathon JM, Martin RW, Fleischmann RM, Tesser JR, Schiff MH, Keystone EC, Wasko MC, Moreland LW, Weaver AL, Markenson J, Cannon GW, Spencer-Green G, Finck BK: Etanercept versus methotrexat in patients with early rheumatoid arthritis: two year radiographic and clinical outcomes. Arthritis Rheum 2002, 46:1443-1450.

9. Moreland LW, Schiff MH, Baumgartner SW, Tindall EA, Fleischmann RM, Bulpitt KJ, Weaver AL, Keystone EC, Furst DE, Mease PJ, Ruderman EM, Horwitz DA, Arkfeld DG, Garrison L, Burge DJ, Blosch CM, Lange ML, McDonnell ND, Weinblatt ME: Etanercept therapy in rheumatoid arthritis: a randomized controlled trial. Ann Intern Med 1999, 130:478-486.

10. Smolen JS, Steiner G: Therapeutic strategies for rheumatoid arthritis. Nat Rev Drug Discov 2003, 2:473-488.

11. Anderson P, Louie J, Lau A, Broder M: Mechanisms of differential immunogenicity of tumor necrosis factor inhibitors. Curr Rheumatol Rep 2005, 7:3-9.

12. Anderson PJ: Tumor necrosis factor inhibitors: clinical implications of their different immunogenicity profiles. Semin Arthritis Rheum 2005, 34:19-22.

13. Wagner CL, Schantz A, Barnathan E, Olson A, Mascelli MA, Ford J: Consequences of immunogenicity to the therapeutic monoclonal antibodies ReoPro and Remicade. Dev Biol (Basel) 2003, 112:37-53.

14. Setoguchi S, Solomon DH, Weinblatt ME, Katz JN, Avorn J, Glynn RJ, Cook EF, Carney G, Schneeweiss S: Tumor necrosis factor alpha antagonist use and cancer in patients with rheumatoid arthritis. Arthritis Rheum 2006, 54:2757-2764.

15. American College of Rheumatology Subcommittee on Rheumatoid Arthritis Guidelines: Guidelines for the management of RA: 2002 Update. Arthritis Rheum 2002, 46:328-346.

16. Bijlsma JW, van Everdingen AA, Huisman M, De Nijs RN, Jacobs JW: Glucocorticoids in rheumatoid arthritis: effects on erosions and bone. Ann N Y Acad Sci 2002, 966:82-90.

17. Da Silva JA, Bijlsma JW: Optimizing glucocorticoid therapy in rheumatoid arthritis. Rheum Dis Clin North Am 2000, 26:859-880.

18. Hong KS, Hack JK, Hyun PK, Lee HJ, Byun SM: Liposomes with antiinflammatory steroid prednisolone palmitate. Drug Dev 1988, 14:765-777.

19. Rauchhaus U, Kinne RW, Pohlers D, Wiegand S, Wölfert A, Gajda M, Bräuer R, Panzner S: Targeted delivery of liposomal dexamethasone phosphate to the spleen provides a persistent therapeutic effect in rat antigen-induced arthritis. Ann Rheum Dis 2009, 68:1933-1934.

20. Metselaar JM, Wauben MH, Wagenaar-Hilbers JP, Boerman OC, Storm G: Complete remission of experimental arthritis by joint targeting of glucocorticoids with long-circulating liposomes. Arthritis Rheum 2003, 48:2059-2066.

21. Metselaar JM, van den Berg WB, Holthuysen $A E$, Wauben $M H$, Storm $G$, van Lent PL: Liposomal targeting of glucocorticoids to synovial lining cells strongly increases therapeutic benefit in collagen type II arthritis. Ann Rheum Dis 2004, 63:348-353.

22. Schmidt J, Metselaar JM, Wauben MH, Toyka KV, Storm G, Gold R: Drug targeting by long-circulating liposomal glucocorticosteroids increases therapeutic efficacy in a model of multiple sclerosis. Brain 2003, 126:1895-1904.

23. Avnir $Y$, Ulmansky R, Wasserman V, Even-Chen S, Broyer M, Barenholz Y, Naparstek Y: Amphipathic weak acid glucocorticoid prodrugs remote loaded into sterically stabilized nanoliposomes evaluated in arthritic rats and in a Beagle dog: a novel approach to treating autoimmune arthritis. Arthritis Rheum 2008, 58:119-129.

24. Dams ETM, Laverman P, Oyen WJG, Storm G, Scherphof GL, van Der Meer JWM, Cortens FHM, Boerman OC: Accelerated blood clearance and altered biodistribution of repeated injections of sterically stabilized liposomes. J Pharmacol Exp Ther 2000, 292:1071-1079. 
25. Ishida T, Ichihara M, Wang X, Yamamoto K, Kimura J, Majima E, Kiwada H: Injection of PEGylated liposomes in rats elicits PEG-specific IgM, which is responsible for rapid elimination of a second dose of PEGylated liposomes. J Control Release 2006, 112:15-25.

26. Ishida T, Wang X, Shimizu T, Nawata K, Kiwada H: PEGylated liposomes elicit an anti-PEG IgM response in a T cell-independent manner. $J$ Control Release 2007, 122:349-355.

27. MacLachlan I, Cullis P: Diffusible-PEG-Lipid Stabilized Plasmid Lipid Particles. Adv Genet 2005, 53:157-188.

28. Pohlers D, Schmidt-Weber CB, Franch A, Kuhlmann J, Bräuer R, Emmrich F, Kinne RW: Differential clinical efficacy of anti-CD4 monoclonal antibodies in rat adjuvant arthritis is paralleled by differential influence on NF- $\kappa \mathrm{B}$ binding activity and TNF- $\alpha$ secretion of T cells. Arthritis Res 2002, 4:184-189.

29. Lasch J, Weissig V, Brandl M: Preparation of Liposomes. Liposomes: A Practical Approach Oxford: Oxford University PressTorchilin VP, Weissig V 2002, 3-30.

30. Van Veldhofen PP, Mannaerts GP: Inorganic and organic phosphate measurements in the nanomolar range. Anal Biochem 1987, 161:45-48.

31. Wisse E: An electron microscopic study of the fenestrated endothelial lining of rat liver sinusoids. J Ultrastruct Res 1970, 31:125-150.

32. Chonn A, Semple SC, Cullis PR: Association of blood proteins with large unilamellar liposomes in vivo. Relation to circulation lifetimes. J Biol Chem 1992, 267:18759-18765.

33. Pelegrí C, Castell M, Serra M, Rabanal M, Rodríguez-Palmero M, Castellote C, Franch A: Prevention of adjuvant arthritis by the W3/25 anti-CD4 monoclonal antibody is associated with a decrease of blood CD4 ${ }^{+}$CD45RC high $T$ cells. Clin Exp Immunol 2001, 125:470-477.

34. Pohlers D, Nissler K, Frey O, Simon J, Petrow PK, Kinne RW: Anti-CD4 monoclonal antibody treatment in acute and early chronic antigeninduced arthritis: influence on T helper cell activation. Clin Exp Immunol 2004, 135:409-415

35. Tamvakopoulos CS, Neugebauer JM, Donnelly M, Griffin PR: Analysis of betamethasone in rat plasma using automated solid-phase extraction coupled with liquid chromatography-tandem mass spectrometry. Determination of plasma concentrations in rat following oral and intravenous administration. J Chromatogr B Analyt Technol Biomed Life Sci 2002, 776:161-168.

36. Damonte G, Salis A, Rossi L, Magnani M, Benatti U: High throughput HPLCESI-MS method for the quantitation of dexamethasone in blood plasma. J Pharm Biomed Anal 2007, 43:376-380.

37. Barrera P, Mulder S, Smetsers Al, Storm G, Beijnen JH, Metselaar JM, van Riel PL: Long-circulating Liposomal Prednisolone versus Pulse Intramuscular Methylprednisolone in Patients with Active Rheumatoid Arthritis [abstract]. Proceedings of the American College for Rheumatology 2008 Annual Scientific Meeting 24-29 June 2008 in San Francisco, L10.

38. Rauchhaus U, Schwaiger FW, Panzner S: Separating therapeutic efficacy from glucocorticoid side-effects in rodent arthritis using novel, liposomal delivery of dexamethasone phosphate: long-term suppression of arthritis facilitates interval treatment. Arthritis Res Ther 2009, 11:R190.

39. Tetlow LC, Lees M, Ogata Y, Nagase H, Woolley DE: Differential expression of gelatinase B (MMP-9) and stromelysin-1 (MMP-3) by rheumatoid synovial cells in vitro and in vivo. Rheumatol Int 1993, 13:53-59.

40. Schmidt-Weber CB, Pohlers D, Siegling A, Schädlich H, Buchner E, Volk HD, Palombo-Kinne E, Emmrich F, Kinne RW: Cytokine gene activation in synovial membrane, regional lymph nodes, and spleen during the course of rat adjuvant arthritis. Cell Immunol 1999, 195:53-65.

41. Hochhaus G, Barth J, al-Fayoumi S, Suarez S, Derendorf H, Hochhaus R, Mollmann $H$ : Pharmacokinetics and pharmacodynamics of dexamethasone sodium-m-sulfobenzoate (DS) after intravenous and intramuscular administration: a comparison with dexamethasone phosphate (DP). J Clin Pharmacol 2001, 41:425-434.

42. Schmidt-Weber CB, Rittig M, Buchner E, Hauser I, Schmidt I, PalomboKinne E, Emmrich F, Kinne RW: Apoptotic cell death in activated monocytes following incorporation of clodronate-containing liposomes. J Leukoc Biol 1996, 60:230-244.

43. Cher DJ, Mossmann TR: Two types of murine helper T cell clone. II. Delayed type hypersensitivity is mediated by Th1 clones. J Immunol 1987, 138:3688-3694

44. Moser DM: The many faces of macrophage activation. J Leukoc Biol 2003, 73:209-212.
45. Yang X: Distinct function of Th1 and Th2 type delayed type hypersensitivity: protective and pathological reactions to chlamydial infection. Microsc Res Tech 2001, 53:273-277.

46. Schmidt-Weber CB, Kinne RW, Voll R, Emmrich F, Buchner E: Experimentelle Anti-Makrophagen-Therapie. Update: Clinical Immunology, Vol. 5 Arthritiden, Therapeutische Perspektiven Lengerich, Berlin, Düsseldorf, Riga, Scottsdale; Arizona, Wien, Zagreb: Pabst Science PublishersSack U 1997, 408-431.

47. Elliott P, Peters RF, White AM: A study of the relationship between glucocorticoid-induced weight loss in rats and the activity of skeletalmuscle and cardiac-muscle ribosomes in vitro. Biochem J 1971, 125:106P-107P.

48. Alberts DS, Garcia DJ: Safety aspects of pegylated liposomal doxorubicin in patients with cancer. Drugs 1997, 54:30-45.

49. Szebeni J: Complement activation related pseudoallergy caused by liposomes, micellar carriers of intravenous drugs and radiocontrast agents. Crit Rev Ther Drug Carrier Syst 2001, 18:567-606.

50. Metselaar JM, Sanders S, van Lamoen R, vam Bloois L, Laverman P, Baranyi L, Savay S, Milosevits J, Wauben MHM, Alving CR, Storm G, Szebeni J: Complement activation-related hypersensitivity reactions caused by pegylated liposomes. PhD Thesis Dept. of Pharmaceutics, Institute of Pharmaceutical Science. Utrecht University, Netherlands 2002, Chapter 8:124-135.

51. Morito T, Oishi K, Yamamoto M, Matsumoto K: Biphasic regulation of Fcreceptor mediated phagocytosis of rabbit alveolar macrophages by surfactant phospholipids. Tohoku J Exp Med 2000, 190:15-22.

\section{doi:10.1186/ar3089}

Cite this article as: Anderson et al:: Liposomal encapsulation enhances and prolongs the anti-inflammatory effects of water-soluble dexamethasone phosphate in experimental adjuvant arthritis. Arthritis Research \& Therapy 2010 12:R147.

\section{Submit your next manuscript to BioMed Central and take full advantage of:}

- Convenient online submission

- Thorough peer review

- No space constraints or color figure charges

- Immediate publication on acceptance

- Inclusion in PubMed, CAS, Scopus and Google Scholar

- Research which is freely available for redistribution

Submit your manuscript at www.biomedcentral.com/submit
C Biomed Central 